\title{
Design and implementation of a navigation control system for slag pot carriers based on combination of active RFID and WiFi technologies
}

\author{
MASOUD GHOLAMI ${ }^{1,2}$ and OMID GHAHRAEI ${ }^{3, *}$ \\ ${ }^{1}$ Department of Electrical Engineering, Majlesi Branch, Islamic Azad University, Isfahan, Iran \\ ${ }^{2}$ Division of Transportation and Logistics, Mobarakeh Steel Company, Isfahan, Iran \\ ${ }^{3}$ Department of Mechanical Engineering, Majlesi Branch, Islamic Azad University, Isfahan, Iran \\ e-mail: o.ghahraei@iaumajlesi.ac.ir; ghahraeiom@yahoo.com
}

MS received 28 December 2015; revised 19 February 2017; accepted 1 August 2017; published online 10 March 2018

\begin{abstract}
The supervision and management of staff and equipment will always result in performance enhancement. In Mobarakeh Steel Company which is located in Iran, the produced slag at electric arc furnaces was transported using slag pot carriers. In the absence of a control system to supervise the performance of these vehicles, managing replacement of slag pots was a challenging and difficult task. Although maintenance of slag pot carriers was expensive and needed specific expertise, there was no online supervisory system to avoid probable failures in vehicles. In order to improve the performance of the supervisory system of the slag pot carriers, a WiFi network was developed in the trajectory of slag pot carriers. Furthermore, the installed RFID-tags alongside the path of the travelling carriers have been read via the RFID-readers installed on the slag pot carriers. Then, the position and speed of the slag pot carriers were calculated and transmitted to the developed software. The performance of the slag pot carriers was improved by implementing the proposed new technology. In addition, stop time rate caused by obstruction of the roads was reduced by $80 \%$. Thereby, systematic, efficient, and optimized slag pot replacement and personnel rotation schedules were developed and the desired productivity was achieved..
\end{abstract}

Keywords. Navigation; RFID; AVL; slag pot carrier; slag.

\section{Introduction}

Effective acquisition and utilization of information in industries can help managers to make better decisions, and consequently resulting in the improvement of productivity. From the transportation administration perspective, realtime information about location and status of the vehicles will result in minimizing congestion and maintenance costs [1]. The availability of the Global Positioning System (GPS) has improved driving conditions and has enhanced the management and supervision of public and industrial vehicles [2]. In electric arc furnaces (EAFs), the impurities in direct-reduced iron and scrap iron are separated from the molten steel during the melting process. These separated materials are known as slag. Since the density of slag is less than that of molten steel, slag is positioned at the top of molten steel, so that it can be removed from the top of molten steel in EAF [3, 4].

Mobarakeh Steel Company possesses eight EAFs in which the produced slag from each furnace is poured in slag pots. The average numbers of pots handled per day are 100 (with $30 \mathrm{~m}^{3}$ capacity) and 15 (with $14 \mathrm{~m}^{3}$ capacity). There are 13 slag pot carriers to handle the

*For correspondence pots which move along the area with a $2 \mathrm{~km}$ radius. The average speed while carrying a full slag pot is about $11 \mathrm{~km} / \mathrm{h}$. Figure 1 shows slag pot carriers while offloading the slag into the slag pool and parked without slag pot. Previously, the traffic management of the slag pot carriers was used by a wireless communication system. That method had several limitations in the management of (a) reducing the time required to replace slag pots, (b) reducing accidents and (c) maintenance of the slag pot carriers.

The time between changing slag pots is crucial and it should be optimized in a way that the suspending time of each EAF for transferring slag into a pot is minimized. Thus, supervision and management of the slag pot carriers play an important role in increasing the productivity of steel company, reducing accidents, improving the operation and maintenance of the machines $[5,6]$.

\section{Methodology}

After conducting a preliminary study on operating conditions of slag pot carriers and their routes, the information regarding the status of the slag pot carriers and their location, the fields and data needed for creating the software 


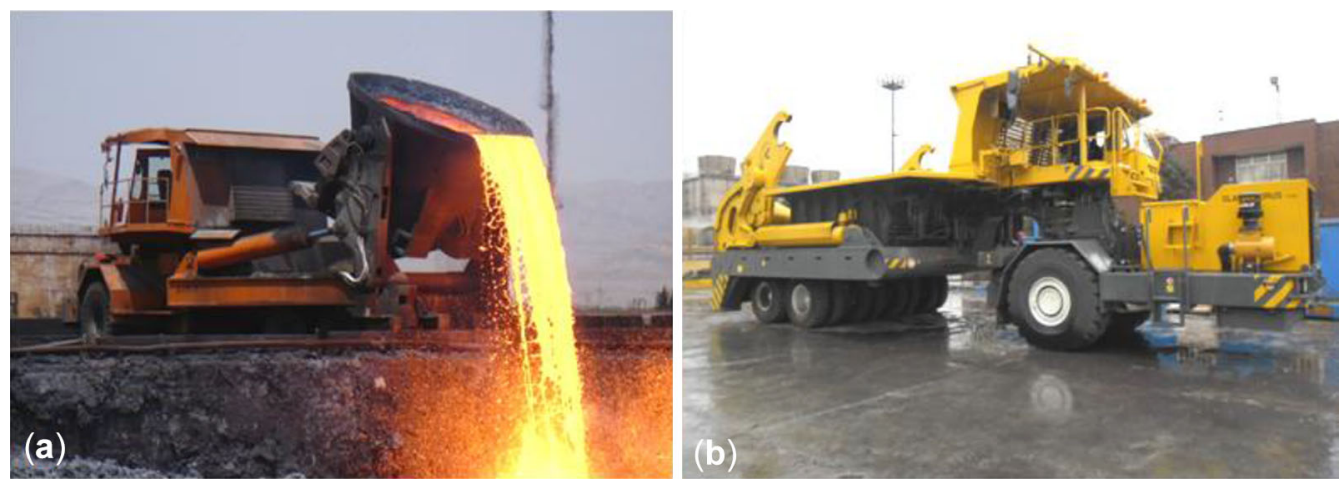

Figure 1. (a) A slag pot carrier while offloading slag into the slag pool. (b) A slag pot carrier without slag pot in the parking.

were identified. The second step was to review the available technologies to process the mentioned fields.

The study concluded that the RFID-tags should be installed at different positions in the route of slag pot carriers and RFID-readers should be installed on the slag pot carriers to transmit real-time positioning data using a local WiFi network. RFID technology was seen as the optimal choice for managing traffic around the furnaces and tracking the engine data.

The precise control and supervision of the routes of slag pot carriers required installation of more than 80 RFIDreaders in the routes along a $2 \mathrm{~km}$ radius from the last EAF to furthest point on the slag pot. However, installation and maintenance of the readers would have been an expensive and challenging task. An alternative solution was to install the RFID-readers on slag pot carriers and the RFID-tags at different locations in the route. Using WiFi interface, each RFID-reader collects information of the RFID-tags and transmit it to the main server. The information would then be transposed onto a simplified map of the steel production unit, stating the location and status of each slag pot carrier. The RFID-tags were installed at $50 \mathrm{~m}$ intervals and each would collect the information within a $50-\mathrm{m}$ radius. Thus, the slag pot carrier would collect the information of each RFID-tag and send all necessary information to the main server.

\subsection{WiFi network}

Using a WiFi network with high frequency requires a fixed wireless nodes being in the line-of-sight of each other [7]. In this study, a high frequency wireless system with mobile wireless nodes (routers installed on the slag pot carriers) was employed for the first time. Using moving wireless nodes causes a high frequency distortion in wireless network, and in some cases results in overlapping the wireless nodes, and consequently decreasing functionality of the system. In order to prevent network interruptions, it was necessary to put router system series in a position on the carrier to ensure reliable transmission to the Slag Dispatch
Center from each location. A dedicated frequency has been set to assure safe communication with no interference.

Each RFID-tag supports a certain area of a moving slag pot carrier. Moving ahead, a slag pot carrier connects to the next RFID-tag determined by the router in terms of frequency range. Thus, a moving slag pot carrier sends and receives data continuously. Each RFID-tag is connected to the Slag Dispatch Center by a separate RFID-reader. The collected data was processed at the server and shown on the screens of the Slag Dispatch Center.

In addition to determining the position of slag pot carriers by using an RFID system, additional information from the carrier's PLC is extracted and transmitted via the wireless network to the Slag Dispatch Center. Thus, the dispatch center can monitor the position of a slag pot carrier along with, driver's ID, speed of the carrier, engine RPM, engine temperature and the weight of the slag pot. Each slag pot carrier has a camera which shares the driver-view with the dispatch center, and an audio communication system which enables a driver to have a bilateral voice communication with the dispatch center.

Instead of the common frequency band $(2.4 \mathrm{GHz})$, a frequency band of $5.8 \mathrm{GHz}$ is utilized for more efficient performance. The first reason for choosing this frequency band is the presence of a huge amount of metal objects in the surrounding area, which requires a higher frequency to eliminate their destructive effects. The second one is due to the moving transmitters and receivers. Each router utilized in this project (under the name RB912UAG-5HPND), operates with a power supply of 8.5 to $30 \mathrm{~V}$ and $14 \mathrm{~W}$ and covers an area of 400-500 $\mathrm{m}^{2}$. Output power of each router is chosen to be $1000 \mathrm{~mW}$ ( $5 \mathrm{GHz}$ ) due to its ability to work at outdoor spaces. The router has two Reverse Polarity SMA (RPSMA) connectors using $802.11 \mathrm{a} / \mathrm{n}$ wireless standard with 150 megabyte/second bank width. Figure 2 shows antennas used for the network on site.

In theory, the $802.11 \mathrm{a} / \mathrm{n}$ wireless standard can transmit audio data packages at the rate of 450 megabyte/second. This standard allows transmission rate of ten times faster than that of the $802.11 \mathrm{~g}$ standard of wireless networks available in the market. It is a suitable standard for audio 

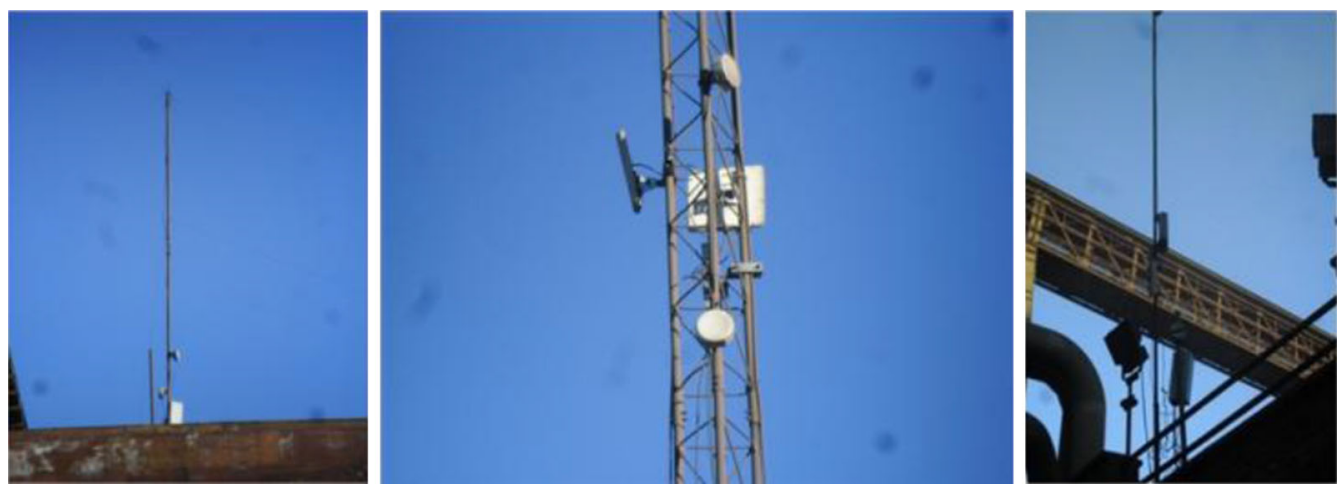

Figure 2. View of antennas used for the network.

and video data transmission. In addition, this standard can reach its maximum speed using data multiplexing and several antennas in a single channel [8,9]. Instead of using access point on each slag pot carrier, there is a router which has $246 \mathrm{~mm} \times 135 \mathrm{~mm} \times 50 \mathrm{~mm}$ dimension. Moreover, four other routers have been installed to insure better network coverage. Additional routers are placed at the following locations:

- in the route of slag pot carriers

- near the dispatch center,

- near the slag pits,

- near the furnaces.

Each single slag pot carrier is not only a simple node at the network; there is a set of transmitters and receivers that comprise the network. Six routers together with the entire slag pot carriers and LTS constitute a network and they communicate with each other (figure 3 ).

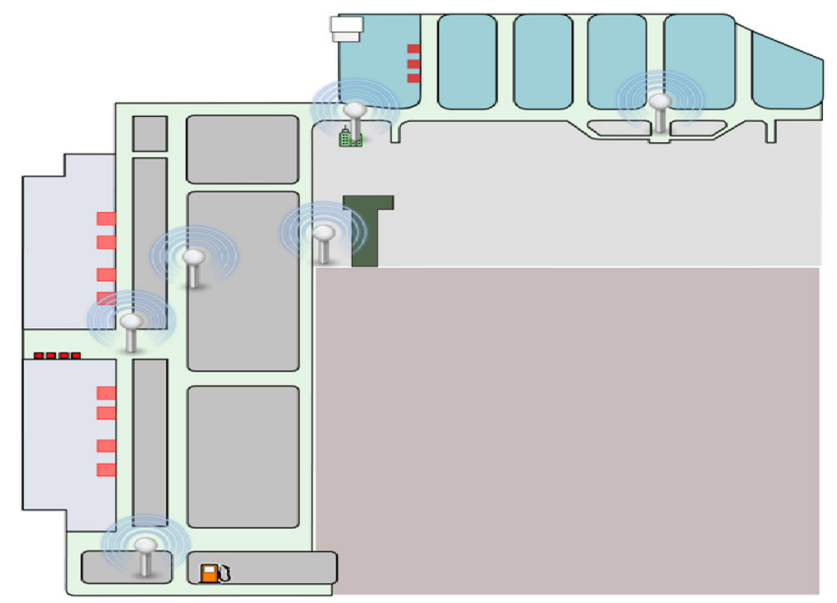

Figure 3. WiFi network in the route of slag pot carriers at Mobarakeh Steel Company.

\subsection{CAN communication system}

Electronic control management (ECM) system (shown in figure 4) stores data collected by sensors on the slag pot carriers. These data are interconnected in the Controller Area Network (CAN). The collected data are decoded and transmitted to the server via WiFi. Within variety of standards such as ABUS, CAN and VAN networks, the CAN standard has been selected for minimizing the wiring and electronic devices [8]. Moreover, the CAN is the most commonly used network in industrial applications, such as slag pot carriers. Data are presented on displays placed in the carrier's cabin which enables a driver to monitor the status of the slag pot carrier. In addition, all parameters of the slag pot carriers and all the driver's actions are monitored at the dispatch center. The Dispatch Officer can send necessary commands to the driver in order to prevent any accident or prevent any breakdown of the slag pot carrier via the installed audio system.

\subsection{Software for slag pots replacement}

Software for slag pot replacement has been written in $\mathrm{C}$ language and it uses a SQL server as its database. The software interface displays the entire map of the slag production unit; locations of furnaces, slag pits, fuel station, roads and maintenance workshop.

The distance between two RFID-tags on the map comprises a zone. The RFID system, in addition to registering the entrance and leaving in each zone, it transmits the data collected by the ECM and PLC to the server. Location of each slag pot carrier on the map, along with other parameters, is then identified on the map using the software. The software allows Dispatch Center Officers to distinguish between different carriers with empty or full pots. The slag pot carriers on the map are presented as moving objects. More precisely, the software displays the trail of each slag pot carrier during each operation using a different colour. Each slag pot carrier's path is illustrated in different colour. 


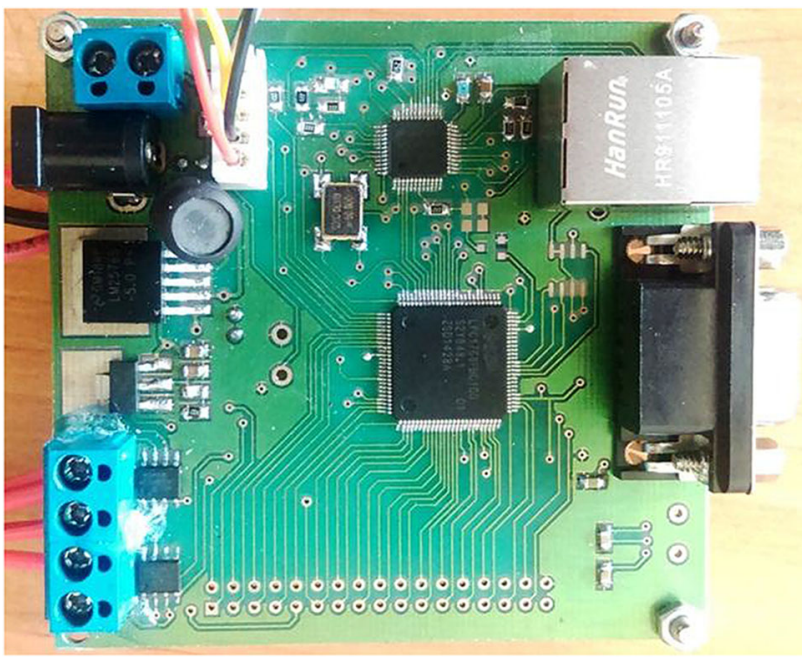

Figure 4. ECM electronic board.

This software allows for the following data to be registered and be presented in a report form:

1. Number of trips (operations) handled by each driver;

2. number of trips (operations) of each carrier;

3. number of zones covered during each operation:

a. Exact time of passing through each zone;

b. speed of carrier in each zone;

c. distance traveled during each operation;

d. time required for each operation.
4. Engine data during each trip (operation)
a. RPM;
b. engine and hydraulic temperatures;
c. error signals on the engine.

5. Weight of empty/filled slag pot;

6 . errors in codes on the carrier.

The mentioned data will allow the dispatch center to supervise and manage the following issues:

1. Drivers availability and their performance;

2. availability of each carrier as one may be in the fuel station or in the workshop for a small repair;

3 . the number of pots handled by each carrier;

4. the number of hours each carrier has operated;

5. pot handling that include number of times a pot has been used, rest period of each pot and number of dumps per each side of the pot.

Figure 5 demonstrates the software's map. In this figure, two slag pot carriers carrying 'full' slag pots are travelling and have been marked by red on the map. The Dispatch Center Officer can simply view the required information by clicking on each carrier, thus he can make better decisions. Each driver not only can track the path it has travelled but also locate all other working slag pot carriers in a real-time manner. Furthermore, the Officer at the dispatch center is able to dispatch the closest slag pot carrier to the furnace. Thus, the Officer can plan the operation of each carrier by

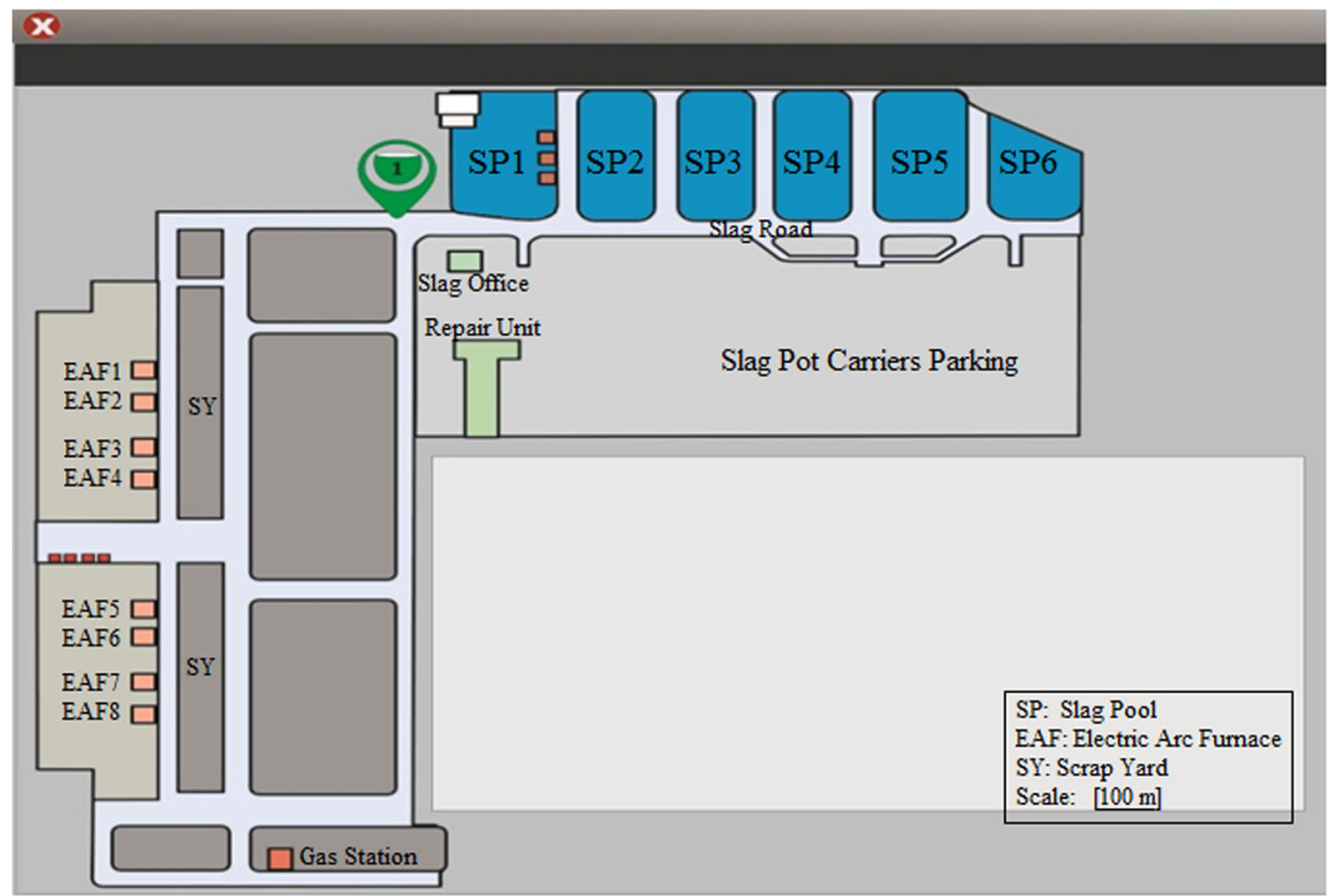

Figure 5. An overview of the map implemented in software. 
minimizing the distance each carrier needs to reach the specific location and the time needed for replacing pots.

In addition to the above mentioned information, the software can collect and provide a report for maintenance of each slag pot carrier. Such data provide a good estimation of the operation and maintenance cost of each carrier. This data can be related to the driver of each carrier. In turn, this will allow for greater accountability by the operator.

\section{Results and discussion}

With respect to the widespread prevalence of GPS and GPRS technologies, location of each slag pot carrier in this project was initially identified using these technologies and the related information was transmitted between the slag pot carriers and server interface GPRS. The same interface was utilized for transmission of audio and text data. Unfortunately, some difficulties arose due to existence of huge and elevated metal structures alongside slag pot carrier's routes, which resulted in inaccuracy in certain GPS location data and delay in data transmission to server because of insufficient coverage caused by inappropriate weather condition. High cost of maintenance and dependency on foreign telecommunication systems and monopolized technologies (such as GPS) were other shortcomings that resulted in seeking an alternative solution [10-12]. By implementing a WiFi network based on the RFID system, the following results were obtained.

\subsection{Time span required to replace a slag pot}

By utilizing the WiFi network, the performance control and management of slag pot carriers have been improved. As shown in table 1 , furnace interrupts caused by slag pot replacements were reduced from $150 \mathrm{~min}$ to $30 \mathrm{~min}$ per month. This high performance was achieved by commissioning the most suitable slag pot carriers to replace slag pots since this process was performed in much shorter time and higher accuracy. Reducing the furnaces' interrupt time was the most valuable achievement of this work, because it prevented imposing extra costs to the Mobarakeh steel production company, and improved the system with higher productivity.

Table 1. A comparison of furnace interruption in a period of one month.

\begin{tabular}{lcc}
\hline $\begin{array}{l}\text { Before } \\
\text { implementation }\end{array}$ & $\begin{array}{c}\text { After } \\
\text { implementation }\end{array}$ & $\begin{array}{c}\text { Decrease in } \\
\text { interruptions }\end{array}$ \\
\hline $150 \mathrm{~min}$ & $30 \mathrm{~min}$ & $80 \%$ \\
\hline
\end{tabular}

Table 2. Sample outputs of the ECM installed on the slag pot carrier number 12 .

\begin{tabular}{lc}
\hline Item & Value \\
\hline Speed & $15 \mathrm{~km} / \mathrm{h}$ \\
Fuel & $70 \mathrm{~L}$ \\
Temperature of oil in engine & $46^{\circ} \mathrm{C}$ \\
Water temperature & $75^{\circ} \mathrm{C}$ \\
Weight of slag pot & $86 \mathrm{Tons}$ \\
Temperature of slag pot & $470^{\circ} \mathrm{C}$ \\
Battery status & $\mathrm{OK}$ \\
Engine operating time & $4567 \mathrm{~h}$ \\
\hline
\end{tabular}

Table 3. Operating report of the slag pot carrier number 9 during one month.

\begin{tabular}{lc}
\hline Item & Value \\
\hline Operating time & $1424 \mathrm{~h}$ \\
Number of trips & 214 \\
Maximum speed & $19 \mathrm{~km} / \mathrm{h}$ \\
Maximum temperature of engine & $85^{\circ} \mathrm{C}$ \\
Date of oil exchange & $21-01-2015$ \\
Date of filter exchange & $21-01-2015$ \\
Date of tires investigation & $21-01-2015$ \\
Last essential repair & $21-12-2014$ \\
Status & Ready-to-work \\
\hline
\end{tabular}

\subsection{Malfunction detection prior to incidents}

This system enables transmission of the engine's technical information, such as temperature and weight of slag pots to the control system. Thus, in case of excessive temperature or weight, the driver receives warnings by voice system based on the set-up network to prevent incidents. Moreover, the engine's information is processed and the driver is called to direct the slag pot carrier to the repair zone, if necessary. By taking these measures, no midway stoppage occurs, thus traffic jam and disorganized movements are prevented. Example of such event signals extracted by electronic board of the ECM of the slag pot carrier number 12 is represented in table 2 . Table 3 shows an operating report for the slag pot carrier number 9 during one month.

\subsection{Higher accuracy in determining slag pot carriers location}

Location of slag pot carriers used to be announced to the control center by drivers using radio, and the dispatching center had to make decisions using the uncertain and insufficient information which was influenced by human error. The accuracy of the information was highly dependent on the viewpoint and experience of the operator and it was sensitive to different operators. Subsequently, based on those reports, assumptions and conceptions the control 
Table 4. Reduction of the damage rate in carriers of Mobarakeh Steel Company.

\begin{tabular}{lcc}
\hline $\begin{array}{l}\text { Before } \\
\text { implementation }\end{array}$ & $\begin{array}{c}\text { After } \\
\text { implementation }\end{array}$ & $\begin{array}{c}\text { Decrease in } \\
\text { interruptions }\end{array}$ \\
\hline 5 times & 1 times & $80 \%$ \\
\hline
\end{tabular}

center was unable to determine the exact location. Consequently, the control center remained unaware of the exact location of slag pot carriers, and whether it was active or not and whether it working properly or malfunctioning. Upon implementation of this project, the exact location of slag pot carriers was determined on the map, and the control center could make decisions based on deterministic information. This has avoided repeated communication with each driver to set the exact location of each carrier The information transmitted from the proposed system was more efficient.

\subsection{Errors and disobeys of drivers}

Upon identification of the carriers' location, drivers have to operate within a certain time schedule and carry the slag pot in that framework. As depicted in figure 5, since drivers are being monitored on the map at the control center, the number of violation from speed limit decreases considerably and they exactly follow the commands issued from the center. The driver identification system is provisioned which makes it possible to register the ID tag of driver of each carrier at any time. Subsequently, in case of occurrence of errors or accidents, the responsible driver is identifiable. In addition, a camera is mounted on the front part of the vehicle which transmits images from the driver's view to the center via the wireless network. Thus, the prepared video can be used at possible future judgements and decision-makings. It also helps to reduce the damage rate inflicted on the carrier, as shown in table 4. In conclusion, this method results in decreasing the errors and disobeys of drivers.

In figure 6 , the number of carriers' trips per month is presented on vertical axis and the identification numbers of slag pot carriers (from 9 to 17) are represented on horizontal axis. As can be seen, speed violation rate is reduced after implementation of this project.

\subsection{Performance of the slag pot carriers}

By utilizing the RFID positioning system, as illustrated in table 5, the solo state of the vehicles' engines has been reduced due to a more efficient management of the navigation system. The overall travelling distance of each slag pot carrier to the furnace is reduced since the location is known on the map and the closest carrier to each furnace is chosen. Therefore, the overall performance of the slag pot carriers has been increased.

As shown in figure 7, prior to implementation of this project, it was unknown how many trips the slag pot carriers have taken. For instance, slag pot carrier number 10 has had the lowest amount of trip, while carrier number 17 (one of the newest vehicle which was highly desired by drivers for driving), had the most number of trips. This resulted in depreciation of a particular slag pot carrier and higher maintenance costs, eventually, degradation in performance of the slag pot carriers. Implementation of the present system resulted in setting a minimum and maximum number of trips per month for each slag pot carrier which resulted in higher productivity.

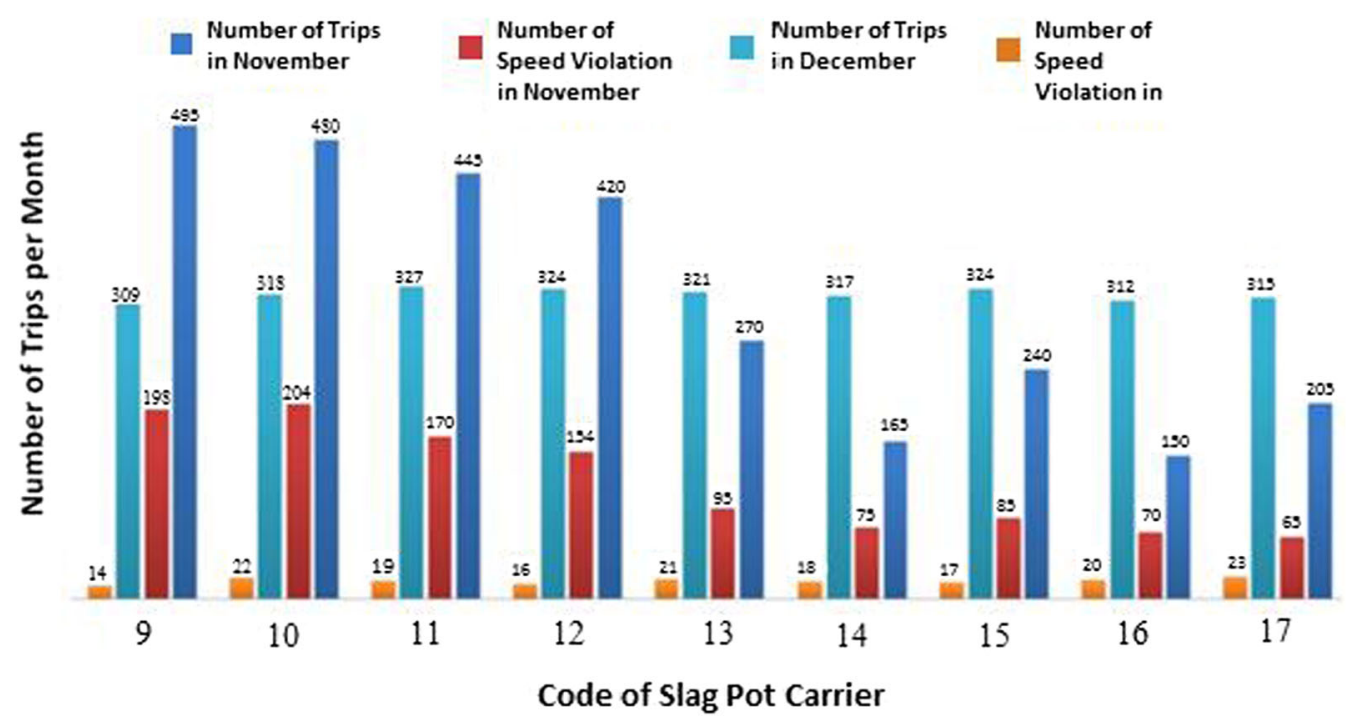

Figure 6. Speed violation chart before and after implementation of the project in terms of number of trips per month. 
Table 5. Comparison between the number of speed violation for different slag pot carriers at before and after implementation of the project (in 2 months).

\begin{tabular}{|c|c|c|c|c|c|}
\hline $\begin{array}{l}\text { Code of slag pot } \\
\text { carrier }\end{array}$ & $\begin{array}{l}\text { Number of } \\
\text { trips }\end{array}$ & $\begin{array}{l}\text { Speed violation before } \\
\text { implementation }\end{array}$ & $\begin{array}{l}\text { Speed violation after } \\
\text { implementation }\end{array}$ & $\begin{array}{l}\text { Before } \\
(\%)\end{array}$ & $\begin{array}{l}\text { After } \\
(\%)\end{array}$ \\
\hline 9 & 520 & 65 & 23 & 32 & 7 \\
\hline 10 & 462 & 70 & 20 & 47 & 6 \\
\hline 11 & 564 & 85 & 17 & 35 & 5 \\
\hline 12 & 482 & 75 & 18 & 45 & 6 \\
\hline 13 & 591 & 95 & 21 & 35 & 7 \\
\hline 14 & 744 & 154 & 16 & 37 & 5 \\
\hline 15 & 772 & 170 & 19 & 38 & 6 \\
\hline
\end{tabular}

Num. of Trips before implementation

Num. of Trips after implementation

----- 2.per. Mov. Avg. (before implementation)

---- 2.per. Mov. Avg. (After implementation)

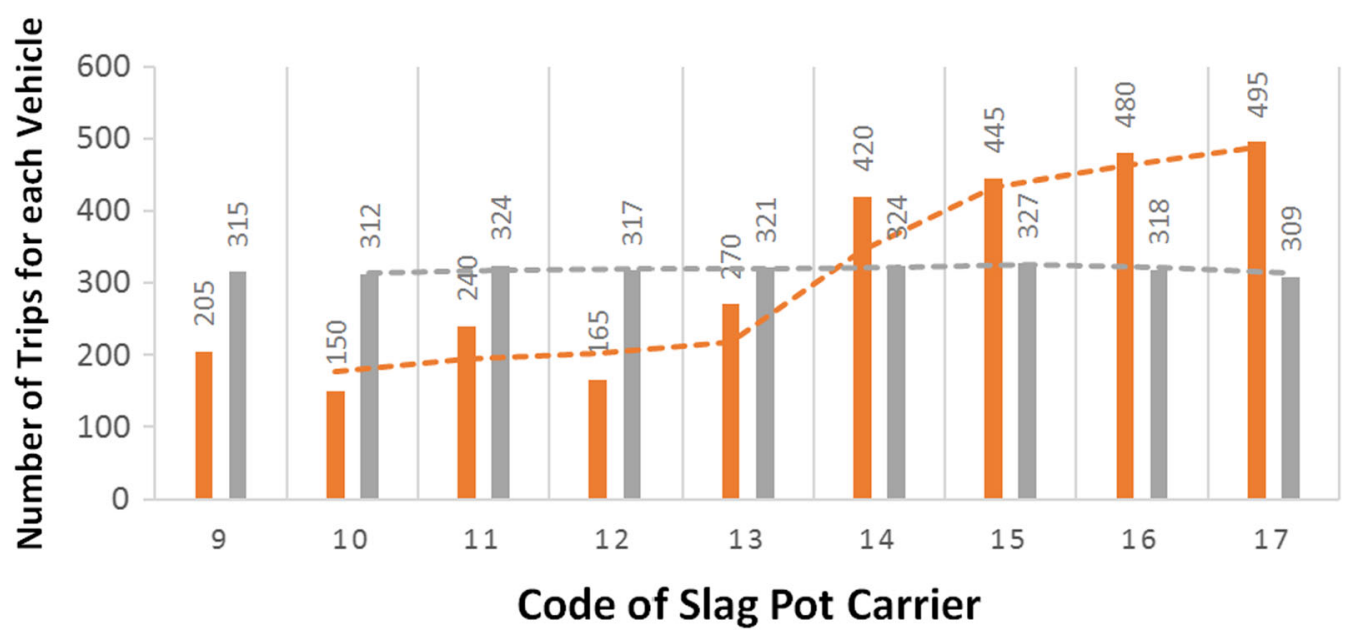

Figure 7. The number of trips and the average of the number of trips for each slag pot carrier per month.

\subsection{Performance of slag pots}

Monitoring the slag pot temperature to prevent pots form damages due to entering molten steel along with slag is an important concern in steel production industry. Upon implementation of thissystem, the body temperature of a slag pot is measured and monitored using the ECM system. If the body temperature is high, a warning will be sent to driver and the dispatching center indicating that this slag pot is not allowed to load slag since it might cause leakage and inflict damages. Consequently, damage in slag pots is limited which resulted in higher cost saving for Mobarakeh Steel Company. Monitoring the temperature of slag pots and prevention of loading the high temperature slag pots resulted in increasing the life cycle of slag pot carriers, and considerable decline in maintenance costs, as shown in tables 6 and 7.
Table 6. Operating report of slag pot number 352 in a period of 1 month.

\begin{tabular}{lc}
\hline Item & Value \\
\hline Number of slag loading & 25 \\
Maximum temperature & $620^{\circ} \mathrm{C}$ \\
Minimum temperature & $20^{\circ} \mathrm{C}$ \\
Number of repairment & 4 \\
Last UT test & $20-08-2014$ \\
Duration of UT test & $20-01-2015$ \\
Status & OK \\
\hline
\end{tabular}

\subsection{Work load of staffs}

Given the critical importance of location and working conditions of slag pot carriers in making plans for handling the slag pots, the drivers and operators at dispatching center 
Table 7. The comparison between repaired slag pots before and after this project.
Number of repaired slag pots before the project

6
Number of repaired slag pots after the project

\begin{tabular}{ll}
\hline 6 & 1 \\
\hline
\end{tabular}

were required to constantly communicate using wireless system. This caused heavy work load and sometimes interrupted their main tasks. Replacing the traditional communication methods by a smart system relieved the staff from the heavy work load.

\section{Conclusion}

During the steel production process, the light impurities of alloys (called slag) were separated from the pure molten steel and were placed on top of the molten steel in electric arc furnaces (EAFs). Slag was poured into slag pots and carried to evacuation ponds by slag pot carriers. The operation required real time information to constantly determine which slag pot carrier was empty and was close to the furnace with a full slag pot. To perform these procedures, an automated positioning system was needed to report the vehicles' location in real-time. To achieve this goal, the prevalent system of AVL based on GPS and GPRS was installed. However, there were challenges in implementation of that system which made it inefficient. Part of which was due to insufficient coverage of satellites at Mobarakeh Steel Company since there are elevated metal structures, inaccurate measurements and dependency to foreign telecommunication systems. Utilization of GPRS also caused dependency to Telecommunication Company and high costs. On the other hand, the vehicles needed to travel in a limited area, and tracking was performed using a local system. By investigating the available technologies, RFID technology was selected for positioning and WiFi technology for transmitting data to the server. These technologies are reasonable for these purposes and to remove the complexities.

Different technologies for positioning such as GPS and RFID have been investigated. Although the GPS is a widespread navigation system, the RFID technology is mostly used for tracking objects. Since Mobarakeh Steel Company needed a safe and secure positioning system, a hybrid system which is based on the RFID and WiFi technologies were proposed for tracking slag pot carriers. In this new system, an RFID-reader is installed on slag pot carriers and active tags are installed alongside the route of slag pot carriers. Then, based on the detected tags during the trajectory of vehicles, the locations of slag pot carriers are identified. One innovation in this system is that tracking is performed using the RFID system, and WiFi infrastructure is used for transmission of data. Thus, this system satisfied the specification of Mobarakeh Steel Company for an efficient, safe and secure positioning and management system.

\section{Acknowledgement}

This work was supported by the Mobarakeh Steel Company, Isfahan in Iran, under contract number 48319647. This project would not have been implemented without the support and guidance of Mobarakeh Steel Company's top management and staff in transportation and support divisions. The authors would also like to thank Parto-Ara Research and Development Group, Isfahan, Iran, and Majlesi Branch, Islamic Azad University, Isfahan, Iran for their support for implementation, installation of the system, and supervision of the project.

\section{References}

[1] Spilker J Jr and Parkinsont B W 1996 Overview of GPS operation and design. In: Global Positioning System: theory and applications, vol. 1, p. 29

[2] Kaplan E and Hegarty C (eds) 2005 Understanding GPS: principles and applications. Norwood: Artech House

[3] Jones J A, Bowman B and Lefrank P A 1998 Electric furnace steelmaking: The Making, Shaping and Treating of Steel, pp. 525-527

[4] Boulet B, Lalli G and Ajersch M 2003 Modeling and control of an electric arc furnace. In: Proceedings of the American Control Conference, vol. 4, pp. 3060-3064

[5] Fruehan R J 1999 The making, shaping, and treating of steel: iron-making, vol. 2. Washington: AISE Steel Foundation

[6] Hafeez K, Griffiths M, Griffiths J and Naim M M 1996 Systems design of a two-echelon steel industry supply chain. Int. J. Prod. Econ. 45(1): 121-130

[7] Milinković M R 2011 Automatic vehicle location (AVL) and fleet management using modern technologies. Inf. Manag. 10(38): 10-14

[8] Pahlavan K 2011 Principles of wireless networks: a unified approach. New York: Wiley

[9] Afanasyev M, Chen T, Voelker G M and Snoeren A C 2010 Usage patterns in an urban WiFi network. IEEE/ACM Trans. Netw. 18(5): 1359-1372

[10] Jarosz A and Finlayson R 2003 GPS guidance system and reduction of open pit mining costs and revenue loss. In: Spatial Sclences, Inaugural Conference of Spatial Sciences Institute, Canberra, ACT, Australia

[11] Lahiri S 2005 RFID sourcebook. Indianapolis: IBM Press

[12] Floerkemeier C and Sarma S 2008 An overview of RFID system interfaces and reader protocols. In: Proceedings of the IEEE International Conference on RFID, pp. 232-240 